\title{
Balancing production and culture: Sustainable agriculture in the Amazon
}

$5 \quad{ }^{1}$ Clubes de Ciencia Bolivia Foundation, Santa Cruz de la Sierra, Bolivia

$6{ }^{2}$ Division of Hematology and Medical Oncology, Department of Medicine, Weill Cornell

7 Medicine, New York, NY, 10065, USA

$8{ }^{3}$ Embassy of Science, Technology and Innovation, Ministry of Foreign Affairs of Bolivia, 9 La Paz, Bolivia

$10{ }^{4}$ Permanent Mission of Bolivia to the United Nations, New York, NY, 10017, USA

11 *Correspondence to mmostajo@rree.gob.bo

13 Sustainable food production in developing countries is challenging, as it requires

14 balancing scalability with respect for local culture and traditions. Bolivia represents a 15 particularly interesting example; with over 36 recognized indigenous groups

16 encompassing over $70 \%$ of the country's population in a relatively small territory, Bolivia

17 is considered one of the most diverse countries in the world (Ferreira et al., 2019).

18 Agriculture in Bolivia employs over $5 \%$ of the country's population and represents over

$1914 \%$ of its GDP. Yet, the introduction of new agribusiness approaches has often been met

20 with resistance by the local communities. For example, the use of transgenic seeds in

21 Bolivia is forbidden by law, with a single exception in soybean production (Avila and

22 Izquierdo, 2006). As result, Bolivia is at a disadvantage in relation to its neighbors in 23 agricultural production. In addition, high costs of transport and export of produce due to 24 the landlocked nature of the country, compounded by logistic difficulties of exporting 
25 through a third country, highlight the need of policies that facilitate a larger and more 26 efficient food production.

In 2019, through Supreme Decree 3973, President Evo Morales authorized

29 Bolivian farmers to implement "controlled burning" of lands in the Amazon, Chiquitano,

30 and Pantanal forests (Rivero, 2019). Known locally as "chaqueo", slash-and-burn

31 agriculture has been commonplace in Bolivia for centuries as an inexpensive means for

32 "land-use change", to clear and fertilize land for agribusiness (Heuberger et al., 2002).

33 That year, however, unprecedented levels of deforestation and unusually high wind

34 speeds rendered the flames uncontrollable and countermeasure deployment proved

35 prohibitively difficult in these isolated regions. Over 2 million hectares of Bolivian forests

36 were burned, resulting in one of the major ecological catastrophes in modern South

37 American history. It is calculated that recovery would take up to 200 years (5).

It is now clear that government-incentivized norms, as well as cultural attitudes

40 towards the use of fire had a large role in the current ecological situation. Regardless of 41 their scientific validity, these attitudes nonetheless reflect the will of sovereign nations. We 42 therefore argue that to successfully develop long-term policies, citizens must be 43 empowered with the scientific literacy to demand environmental responsibility and 44 cooperation with international agencies. It is only through effective education that citizens 45 and politicians can recognize--and critically evaluate--the real-world outcomes of 46 environmental policies. Given the history of resistance to philanthropic efforts backed by

47 industrialized economies, the temporal sustainment of such support is critical to fostering 48 mutual trust (Bonilla-Aldana et al., 2019). For instance, foreign efforts, including the 49 "Amazonia without fires" program, have not achieved sufficient traction within local groups 50 (Bonilla-Aldana et al., 2019). Past experiences suggest that participatory educational 
51 approaches provide a promising avenue for transmission of relevant scientific concepts,

52 while encouraging interest and action in the issues at hand (Figure 1) (Ferreira et al., 2019;

53 Carosso et al., 2019).

54

55 The recent ascent of Jeanine Añez to the presidency of Bolivia has dramatically

56 changed the diplomatic landscape of the country. Implementing an "open-borders" policy

57 that stands in contrast to her predecessor's, the new administration has received strong

58 support from developed economies, including the United States and the European Union

59 (Jourdan, 2020). The new government has highlighted technology exchange and

60 reforestation as high priorities for the country (Saucedo-Bendek et al., 2020). We therefore

61 hope that allied nations will commit to arming local governments and communities with

62 sustained expertise needed to manage future fire risks. New public policies should

63 prioritize the incorporation of low-cost alternatives to slash-and-burn agriculture, as well

64 as educating farmers in fire behavior and risk management (McDaniel et al., 2006).

65 Specific measures that have demonstrated efficacy in similar contexts include, but are not

66 limited to, the development of cash-transfer programs, tax regulations, and other

67 economic incentives (Jacobi et al., 2017), as well as agronomic approaches that increase

68 nitrogen fixation and land fertility (Calle, 2020), therefore reducing the need of slash-and-

69 burn agriculture (Figure 1).

70

71 Bolivia represents an important opportunity for empirically-informed, and

72 consistent, global outreach to local and rural groups. It is only through sustained

73 international attention that the most objectively detrimental impacts of human activity--not

74 merely those attracting temporarily attractive histrionics--can be counteracted with long-

75 term environmental protection. 


\section{COMPETING INTERESTS}

78 M.A.M.-R. is the Bolivian Science, Technology and Innovation Ambassador. The 79 authors declare no other conflict of interest.

80

\section{AUTHOR CONTRIBUTIONS}

All authors wrote this manuscript.

85 Figure 1. Sustainable agriculture in the Amazon. Development of long-term 86 sustainable agriculture in the Amazon requires participatory education approaches to shift

87 cultural attitudes towards fire usage and evidence-based regulations.

88

\section{References}

Avila, T., Izquierdo, J. (2006). Management of the appropriate agricultural

91 biotechnology for small producers: Bolivia case study. Electronic Journal of Biotechnology

92 9, 1-7. doi: 10.2225/vol9-issue1-fulltext-4

93

94 Bonilla-Aldana, D.K., Suárez, J.A., Franco-Paredes, C., Vilcarromero, S., Mattar, 95 S., Gómez-Marín, J.E., et al. (2019). Brazil burning! What is the potential impact of the 96 Amazon wildfires on vector-borne and zoonotic emerging diseases? - A statement from

97 an international experts meeting. Travel Medicine and Infectious Disease 31, 101474.

98 doi: 10.1016/j.tmaid.2019.101474

99 
101 Ambio. 49, 593-604. doi: 10.1007/s13280-019-01224-8

102

103 Carosso, G.A., Ferreira, L.M.R., Mostajo-Radji, M.A. (2019). Scientists as non-

104 state actors of public diplomacy. Nature Human Behaviour. 3, 1129-1130. doi:

105 10.1038/s41562-019-0716-1

106

107 Ferreira, L. M. R., Carosso, G. A., Duran, N. M., Bohorquez-Massud, S. V.,

108 Vaca-Diez, G., Rivera-Betancourt, L. I., et al. (2019). Effective participatory science

109 education in a diverse Latin American population. Palgrave Communications. 5:63. doi:

$110 \quad 10.1057 / \mathrm{s} 41599-019-0275-0$

111

112 Heuberger, K., Fredericksen, T., Toledo, M., Urquieta, W., Ramirez, F.

113 Mechanical cleaning and prescribed burning for recruiting commercial tree regeneration

114 in a Bolivian dry forest (2002). New Forests. 24, 183-194. doi:

115 10.1023/A:1021369921935

116

117 Jacobi J., Rist S., Altieri, M. (2017). Incentives and disincentives for diversified 118 agroforestry systems from different actors' perspectives in Bolivia. International Journal of

119 Agricultural Sustainability. 15, 365-379. doi: 10.1080/14735903.2017.1332140 120

121 Jourdan, A. (2020).m U.S. to Send Ambassador to Bolivia for First Time in Over

122 a Decade. https://www.usnews.com/news/world/articles/2020-01-23/us-to-send-

123 ambassador-to-bolivia-for-first-time-in-over-a-decade.

124 
125 McDaniel J., Kennard D., Fuentes, A. (2006). Smokey the Tapir: Traditional Fire 126 Knowledge and Fire Prevention Campaigns in Lowland Bolivia. Society \& Natural 127 Resources. 18, 921-931. doi: 10.1080/08941920500248921

128

129 Saucedo-Bendek, O., Ewel, S., Roman-Roig, F.J. (2020). Entrepreneurs'

130 Perception Toward International Cooperation and Government Programs Concerning

131 Entrepreneurship. Frontiers in Education. 5, 57. 10.3389/feduc.2020.00057

132

133 Rivero, C.P. (2019). Posibles efectos por la modificación del decreto supremo

13426075 sobre tierras de producción forestal permanente. CIPCANotas.

135 http://cipca.org.bo/analisis-y-opinion/cipcanotas/posibles-efectos-por-la-modificacion-

136 del-decreto-supremo-26075-sobre-tierras-de-produccion-forestal-permanente. (2019). 
Participatory Approaches

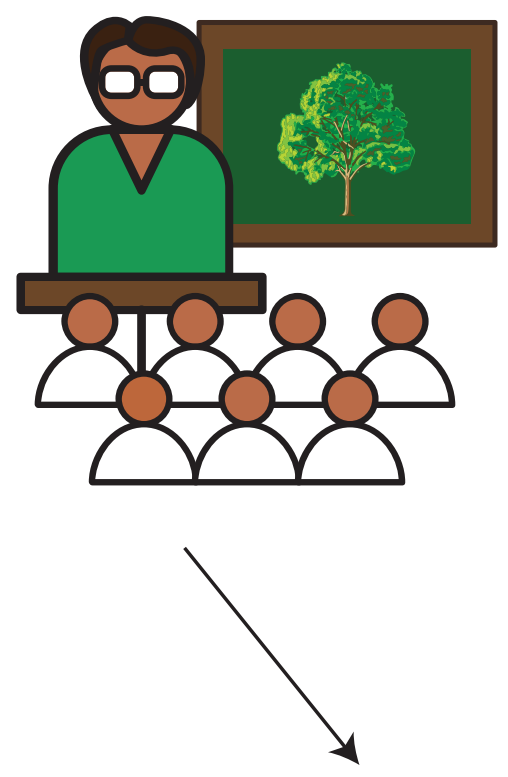

Evidence-based Policy

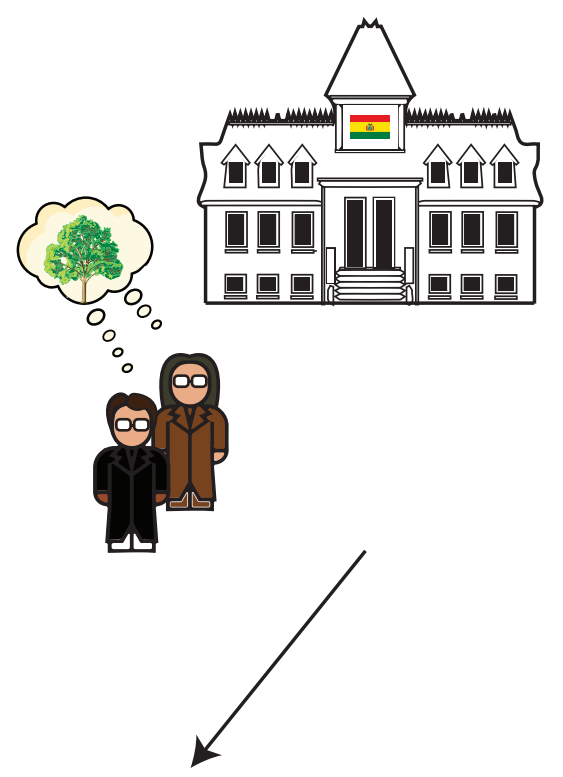

Sustainable Agriculture

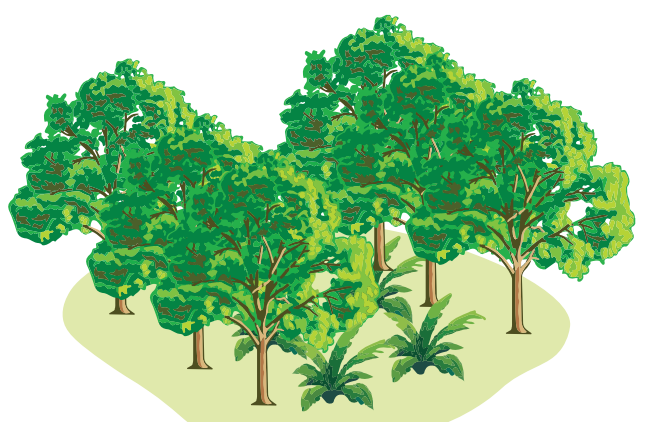

Figure 1

Gandarilla et al 